DOI: 10.32743/UniTech.2021.85.4-5.28-33

\title{
TECHNOLOGY OF PERSONALLY ORIENTED ADAPTIVE LEARNING SYSTEMS
}

\author{
Maksadkhon Yakubov \\ Professor, doctor of technical sciences, \\ Tashkent University information technologies named after Muhammad al-Khwarizmi, \\ Uzbekistan, Tashkent
}

Nasibakhon Rasulova

Assistant,

Tashkent University of Information Technologies named after Muhammad al-Khwarizmi

Uzbekistan, Tashkent

E-mail: nrasulova1977@gmail.com

\section{ТЕХНОЛОГИЯ ЛИЧНОСТНО-ОРИЕНТИРОВАННЫХ АДАПТИВНЫХ ОБУЧАЮЩИХ СИСТЕМ}

\author{
Якубов Максадхон Султаниязович \\ профессор, д-р. техн. наук, \\ Ташкентский Университет информационных технологий \\ имени Мухаммада ал-Хоразмий, \\ Республика Узбекистан, г. Ташкент \\ Расулова Насибахон Юсуфжановна \\ ассистент, \\ Ташкентский Университет информаичонных технологий \\ имени Мухаммада ал-Хоразмий \\ Республика Узбекистан, г.Ташкент
}

\begin{abstract}
The article discusses the use of intelligent learning systems in blended education based on an individualized approach. The relevance of the development of multi-agent systems in the creation of innovative adaptive intelligent environments for online learning based on the use of various approaches and system analysis is shown in this article. Schemes for an intelligent teaching system based on student and teacher models are presented in this article. The importance of individualization of electronic and distance education for students with different levels of knowledge and the prospects for their development are shown.

В статье рассматривается применение интеллектуальных обучающих систем в смешанном образовании на основе индивидуализированного подхода. Показана актуальность разработки мультиагентных систем при создании инновационных адаптивных интеллектуальных сред для онлайн обучения, основанных на применении различных подходов и системном анализе. Приведены схемы для интеллектуальной обучающей системы, основанные на моделях студента и преподавателя. Показана важность индивидуализации электронного и дистанционного образования для обучающихся с различными уровнями знаний и перспективы их развития.
\end{abstract}

Keywords: intelligent learning system, adaptive system, student model, individualization of teaching.

Ключевые слова: интеллектуальная обучающая система, адаптивная система, модель студента, индивидуализация обучения.

The current stage in the development of educational activities is determined by the dominance of information and communication technologies, which make it possible to intensify the forms and methods of traditional approaches to teaching. An increasing number of people are striving to get an education with minimal time losses, as the pace of life leaves less and less time for traditional full-time education. The principles of organizing the educational process are gradually changing, conditions are being created for the implementation of dynamic personalized learning.

E-learning is understood as the organization of educational activities using information contained in databases and used in the implementation of educational

Bibliographic description: Yakubov M.S., Rasulova N.Y. Technology of personally oriented adaptive learning systems // Universum: технические науки : электрон. научн. журн. 2021. 4(85). URL: https://7universum.com/ru/tech/archive/item/11577 (дата обращения: 26.04.2021). 
programs and information technologies, technical means, as well as information and telecommunication networks that ensure the transmission of this information through communication lines, interaction between students and pedagogical workers. ... Distance learning technologies are understood as educational technologies implemented mainly with the use of information and telecommunication networks with indirect (at a distance) interaction between students and teachers.

Among the main advantages of this training are the following:

- each student gets the opportunity to master the necessary knowledge and skills in a convenient format;

- planning and understanding what training needs should be met and what results will bring;

- providing effective learning management tools;

- reducing the time and financial costs of training, without losing the advantages of the traditional approach;

- technology and teaching enrich and complement each other;

- active social interaction of trainees both with each other and with teachers;

- availability of the teacher is almost constant;

- training is possible regardless of time and place;

- variety of didactic approaches;

- improving the quality of education (including through the use of more effective teaching aids);

- individual control over training;

- natural development by students of modern means of organizing work, communications;

- priority of the student's independent activity;

- organization of individual support for the educational activities of each student;

- using the organization of group learning activities;

- flexibility of the educational trajectory;

- integration of online and offline educational and methodological content of reusable use. [1, p.263]

- E-learning technologies provide multimedia content that is timeless and timeless for learners with different capabilities and needs. The combination of online and offline elements makes training effective, cost-effective and convenient, and the educational process is interactive, person-centered and adaptive for all parties interested in training.

- Introduction to the educational process of blended learning allows you to solve a number of problems:

- 1) for trainees:

- expanding the educational opportunities of students by increasing the availability and flexibility of education, taking into account their individual educational needs, as well as the pace and rhythm of mastering the educational material;

- implementation of individual curricula with an unlimited choice of subjects, the level of their development and methods of organizing educational activities;

- - personalization of the educational process: the student independently determines his educational goals, ways to achieve them, taking into account his educational needs, interests and abilities;
- maximum objectification of the assessment procedure and results;

- - stimulating the formation of the subject position of the student: increasing independence, social activity, motivation of cognitive activity;

- obtaining individual counseling from a teacher to overcome difficulties in mastering the educational material and fill gaps in knowledge;

- 2) for teachers:

- professional development of teaching staff;

- Acquisition of qualification competencies aimed at the implementation of a new generation of SES;

- - increasing the effectiveness of teaching activities in order to achieve new educational results;

- the use of new types of control and communication in the pedagogical process;

- the ability to organize quality work with highly motivated students;

- - transform the style of the teacher: move from the translation of knowledge to interactive interaction with the student, which contributes to the construction of students' own knowledge;

- 3) to organize the educational process:

- - the possibility of saving money by increasing the level of effectiveness of pedagogical activity.

- - attracting an additional contingent of students through the organization of multidisciplinary training;

- - solving the problem of the shortage of teaching staff;

- - intensification of educational activities in order to save time for the implementation of other educational and cultural needs;

Thus, blended learning is characterized by the preservation of the general traditional principles of building the educational process with the inclusion of elements of Internet learning. The ratio of these two forms of education is determined by the readiness of the educational institution for such a structure of the educational process, as well as the desire and technical capabilities of students [2, p. 57].

Technology is transforming education, and its influence is constantly growing. Blended learning is a promising learning system that combines the benefits of traditional and interactive learning. In our opinion, the development of a blended form of education can become one of the key areas of modernization of the entire educational sphere.

Digital technologies have created the problem of finding the necessary information in a "reasonable" time in the huge databases of modern information systems, which makes it almost impossible to use them in the educational process without preliminary settings, creating special filters and systems for finding the necessary information for educational and educational tasks.

In modern conditions, many educational institutions are automating those teaching methods that have been accumulated in the course of traditional approaches to education. Many specialists try to adapt and use the latest information technologies in the educational process.

The following approaches and technologies that are significant in the development of educational processes 
can be named: service-oriented architectures, cloud technologies and virtualization, intelligent dynamic systems, multi-agent systems, ontologies, and evolving knowledge.

Cloud technologies are web-based data access technologies that enable a user to host, deliver, and use applications and computing resources. The necessary applications and the resources used become available via the Internet in the form of service functions (services) and which are used on various hardware platforms and devices.

Intelligent dynamic systems allow you to create subsystems for the formation of individual learning paths and maintain an individual learning environment. An intelligent dynamic system is the result of the integration of intelligent systems with dynamic systems. They are two-tier dynamic models. One of the levels of the model is responsible for the strategic functions of the behavior of the system, and the other level fulfills the tasks of implementing a specific (including mathematical) model [3, p. 325]

Within the framework of intelligent dynamic systems, it is possible to create a subsystem for the formation of individual learning paths and maintain an individual learning environment.

The architecture of intelligent information systems (ITS), based on an agent-based approach, is understood as the conditional division of a multi-agent system (MAS) into interacting intelligent agents, where each agent performs certain functions, and the ITS knowledge base consists of an integrated knowledge base of its agents.

The ontological approach underlies the creation of a resource of educational objects with their metadata. The resource of competency ontologies is a distributed system based on modern network technologies. To construct a resource of competencies ontologies, a client-server model is used [4, p. 176].

In conditions of mass scale and continuity of the learning process, a large number of controlled parameters, a variety of individual ways of students' activity, the need to manually maintain a lot of statistical records leads to the fact that the teacher is exposed to a significant information load, which weakens control over the learning process. This leads to a number of negative consequences:

- knowledge is checked selectively, as a result of which deviations arising in the course of training cannot be noticed and corrected by the teacher in time;

- the queue to the teacher at the control stages creates a waste of time for the trainees and contributes to the deterioration of the psychological climate;

- the teacher's explanations are designed for an abstract average student without taking into account his individual abilities, as a result - the contradiction between the average presentation of the educational material and his individual perception;

- weak self-control: the trainee does not receive information about his work on time, which does not stimulate an increase in his activity, etc.

- From the foregoing, it follows that new learning technologies are needed that would allow:
- to recreate in the minds of students a holistic idea of the object of study;

- to bring the learning process closer to the real conditions of activity in order to purposefully form practical skills and extra-logical knowledge, namely, various types of intuition, the ability to make decisions in conditions of uncertainty, foresee, predict, etc .;

- ensure the collection and processing of information necessary for the organization of optimal management of learning, free the teacher from non-creative types of work;

- individualize the learning process;

- $\square$ activate the cognitive process of the learner, relying on the development of independence, selfgovernment, self-control, etc.

One of the ways to solve this problem can be the introduction of intelligent learning systems into the learning process to intensify the transfer and consolidation of knowledge, and reduce overhead at all levels of the learning process.

Intelligent learning systems consist of two parts: the main part, which includes educational information (educational content), and the auxiliary part, which implements the intelligent control of the educational process. The main part of the program consists of the following modules: information, modeling, calculation and control. The main part of the system includes all sorts of educational information: text, tables, figures, animation and video clips. The text can contain active windows that allow the user to move deeper into the screen, move along an arbitrary trajectory from one section to another, concentrating attention on the necessary information, and make an arbitrary choice of the sequence of familiarization with the information. The information module includes a database and a knowledge base for educational purposes. The database contains educational, informational, reference material, a list of trainees, progress, etc. In the process of creating a knowledge base, you can use the full range of didactic capabilities of multimedia, hypermedia and telecommunications technology [5, p. 72].

Analysis of the current state of information technology and telecommunications means that the following principles of the structure of information and educational environments can be formulated:

Multicomponent - an intelligent training system is a multicomponent environment that includes educational and methodological materials, high-tech software, training systems, knowledge control systems, technical means, databases and information and reference systems, information storage of any kind, including graphics, video and etc., interconnected.

Integrity - the information component of the ITS should include all the necessary set of basic knowledge in the fields of science and technology with access to world resources, determined by the profiles of training specialists, take into account interdisciplinary connections, an information and reference base of additional educational materials that detail and deepen knowledge.

Distribution - the information component of the ITS is optimally distributed among the information storages 
(servers), taking into account the requirements and limitations of modern technical means and economic efficiency.

Adaptability - the information and educational environment should not be rejected by the existing education system, should not violate its structure and principles of construction, it should also allow flexible modification of the information core of the IEE, adequately reflecting the needs [6, p. 503].

The formulated principles of building ILE make it necessary to consider the information and educational environment, on the one hand, as a part of the traditional educational system, and, on the other hand, as an independent system aimed at the development of active creative activity of students using new information technologies.

Intelligent training system - a training system with elements of artificial intelligence. Such a system (adaptive training system) allows not only to train the student and control his knowledge, but also, based on the results of the student's activity, can determine what knowledge is insufficient or erroneous and return the student to the corresponding section of theory or practice, or provide additional explanations. Those. it allows you to adapt the learning process to the characteristics of each individual student working with the system. Thus, each student goes through an individual learning path, and receives individual knowledge [6, p. 505].

By adaptability we mean the personification of the learning process based on a system that takes into account the individual characteristics of students, including psychological characteristics, speed of perception, level of initial knowledge, as well as individual goals and objectives of learning.

A simplified diagram of an intelligent training system is shown in Fig. 1.A. It has several main components: a subsystem for the formation of a training course, a learning subsystem (presentation of material), a knowledge control subsystem (selection or generation of control tasks).

A)

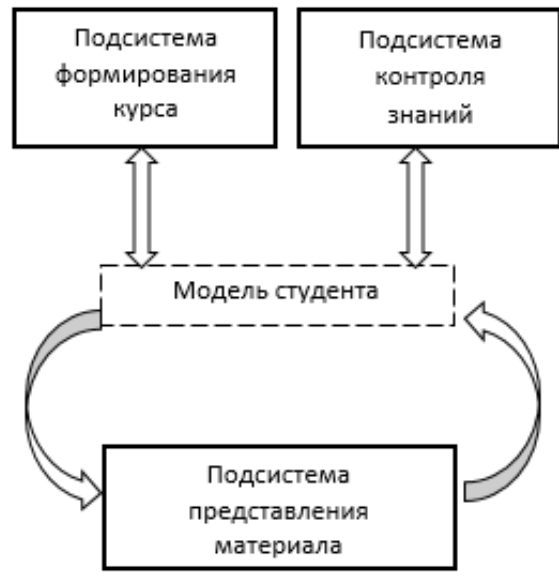

B)

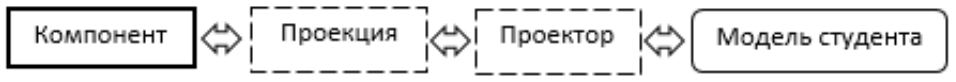

Figure 1. Scheme of the intelligent teaching system (A) and the architecture of the student model (B)

Adaptation is achieved as a result of using a student's model (learner's model), which is an image of a user in the system, its unified representation, and the rules for changing it.

The learner's model should include information:

- about the purpose of training;

- about the initial knowledge of the student;

- about the knowledge of the student within the framework of the studied course (the current state of the learning process);

- about the individual characteristics and characteristics of the student;

- about the peculiarities of the presentation of educational material;

- about the rules of knowledge control;

- about the rules for changing the student's model based on the results of the student's work with each of the components of the system.
The main task of the learner model is to generate the best learning action.

The student's model can be used by all components of the teaching system, due to which they are adapted to the current level of the student, understanding, knowledge. The student's interaction with any of the components of the system is reported by the student model. This ensures the continuity of learning: the results of a student's work with any of the components are immediately reflected in the student's model and can be taken into account by other components that adapt their work to changed knowledge or characteristics. Those. each module can not only use the student's model for adaptation, but also influence it, reflecting new data and experience that the student demonstrated while working with this module [7, p. 24].

Thus, the student model can be viewed as the core of an intelligent teaching system. 
To ensure the openness of the architecture and flexibility of the system, you can use projections and rules (Fig. 1. B). The student model is divided into two parts, the main student model and the projection.

The main student model is at the center of the environment and collects information about a given student from various sources. The student's interaction with any of the components of the system is reported by the student model. For example: "at time T1, the student visits the hypernode of $\mathrm{C} 1$ for $\mathrm{S} 1$ seconds", "at time $\mathrm{T} 2$, the student was shown an example of solving a problem that concerns the concepts $\mathrm{C} 1, \ldots, \mathrm{Cn}$ ", "working with the editor at time T3, the student has successfully used the concepts $\mathrm{C} 1, \ldots$, See ". These messages are time stamped and stored as standard events directly associated with the nodes of the problem domain model. No further processing is performed to avoid losing important information. The basic student model brings together all information about the student that can be used for adaptation. The ILE components do not directly use the student model, but instead use projections.

Projection is a local view of the student, representing that information from the student's model that is essential for a particular component of the system in order to adapt his work to the student.

The projection is created from the main student model with a special set of rules - a projector. Each component has its own projection and projector, which provides an interface between the component and the main student model.

One part of the projector rule is used to project the student's main model into a local projection. For example: "if a student reads the description of the structure $\mathrm{Ci}$, and the student views the work of the structure $\mathrm{Ci}$ with the first visualization level more than 15 times, then set the second visualization level for the structure $\mathrm{Ci}$ ". The second part of the projector is used to provide backprojection: the results of the student's work with the component into the main student model. For example: "if at time $\mathrm{T} 1$ the student visits the hypernode for the concept $\mathrm{Ci}$ for more than 30 seconds, then at time $\mathrm{T} 1$, the student reads the description of the concept Ci." Thus, the student's model acts in the intellectual system as a component that provides the student with the "optimal" for him the next teaching influence, the level of visualization or the details of the reference. In fig. 2 shows a model of a learning adaptive system using a student model as an adaptive component.

An adaptive learning system is a hybrid system based on intelligent and distance learning technologies, designed to teach users knowledge, skills and abilities in a set of disciplines for mastering a specialty. The student model in this case can be represented as a knowledge base based on an object-oriented presentation model. System components work with individual projections that are stored in working memory.

The subsystem for the formation of the course uses a projection to form a sequence of studying subjects of disciplines, taking into account the knowledge of the student and the results of the fulfillment of control tasks.

The knowledge control subsystem uses the projection of the student's model to generate or select control tasks, taking into account the passage of the material in accordance with the learning objectives.

The learning subsystem provides educational material in the optimal volume, taking into account the individual psychological, physical and other characteristics of the student, as well as the speed of perception of various presentation of the material and learning goals.

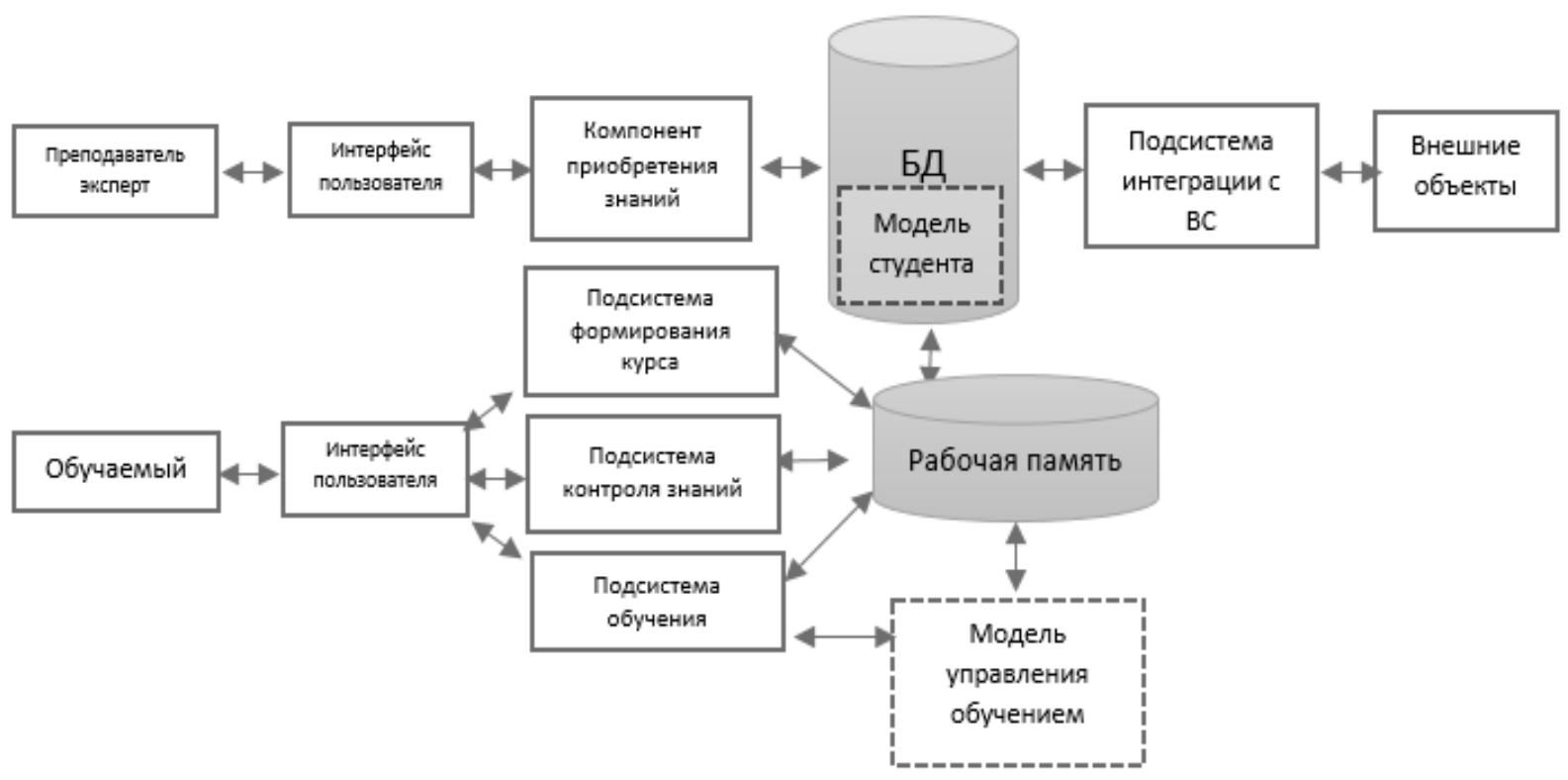

Figure. 2 Model of the training adaptive system 
The results of the work of each of the components are reported to the student's model for the subsequent generation of modified projections.

So, the student's model is the core of the intellectual part of the teaching system and provides an opportunity to adapt the learning process to the characteristics of each specific student.
A model of adaptive management of the learning process has been developed, in which adaptation is based on an overlay model of the student's skills, presented as a set of pairs "operation (rule) - value". On the basis of the overlay model of skills, adaptive control of the trainee is provided, which consists in issuing to him for the next step of training an educational task of optimal difficulty and complexity.

\section{Reference:}

1. Rasulova N., Salieva D. Fuzzy logic in creating adaptive intelligent learning // InterConf. - 2021 .- S. $262-270$.

2. Nagaeva I.A. Blended learning in the modern educational process: necessity and opportunities // Domestic and foreign pedagogy. 2016. No. 6 (33). URL: https://cyberleninka.ru/article/n/smeshannoe-obuchenie-v-sovremennomobrazovatelnom-protsesse-neobhodimost-i-vozmozhnosti (date of access: 03.01.2021).

3. Rasulova N. Specific features and distinctive features of online training systems // InterConf. - 2021.

4. Brusilovsky P.L. Adaptive Learning Systems in the World Wide Web: an Overview of Available Technologies. International Forum of Educational Technology \& Society. Available at: http://ifets.ieee.org/russian/depository/WWWITS.html (accessed: 09/13/2020).

5. Kurganskaya G.S. Cloud Technologies of the Internet Education Based on KFS Knowledge Representation Model. Vestnik burjatskogo gosudarstvennogo universiteta [Bulletin of the Buryat State University]. 2013. no. 9. pp. 69-75.

6. Kristensen T., Lamo Y., Hinna K.R., Hole G.O. Dynamic Content Manager - A New Conceptual Model for E-Learning. Proceedings of the International Conference on Web Information Systems and Mining (WISM '09). Springer-Verlag, Berlin, Heidelberg, 2009. pp. 499-507.

7. Solovov A.V. Mathematical Models of Content and Processes of E-learning. Telekommunikacii i informatizaciya obrazovaniya [Telecommunications and Informatization of Education]. 2006. no. 4. pp. 20-37. 